\title{
Inhalt
}

Vorwort

FRANZISKA WENZEL

Intermediale und intramediale Übertragung.

Mittelalterliche Bezeichnungspraktiken in metaphorischer Rede und Illustration

Intermediale Übertragungen I:

Diagrammatische und sinnbildliche Darstellungsverfahren

DAVID GANZ

Inlibration. Buchwerdung und Verkörperung in einem frühmittelalterlichen Evangeliar

HENRIKE MANUWALD

Der nichtverbrennende Dornbusch und die Jungfrau Maria.

Überlegungen zur Diagrammatizität typologischer Sinnbilder

ECKART CONRAD LUTZ

Zur Medialität von ,Literaturkatalogen“ in Wort und Bild:

Gottfried von Strassburg, Rudolf von Ems und Thomasin von Zerclære,

der Psalter des Robert de Lisle und die Süddeutsche Tafelsammlung

Intermediale Übertragungen II:

Ikonische und topische Darstellungsverfahren

PIA SELMAYR

Die Intermedialität von Text und Bild im Bezug auf die unterschiedlichen

Übertragungsphänomene des jüngeren Sigenot

HERFRIED VÖGEL

Begriff, Bilder und Bildlichkeit des Kriegs in Mittelalter und früher Neuzeit

TOBIAS BULANG

Minne und Jagd - Metaphorische Übertragungen und konzeptionelle Konkurrenzen zwischen Liedern und Miniaturen im Codex Manesse

GERT HÜBNER $(\dagger)$

Metaphorische Sprichwörter in Text und Bild um 1500:

Narrenschiff und Ulenspiegel 


\section{Intramediale Übertragungen:}

Poetologische Darstellungsverfahren

HOLGER RUNOW, JULIA ZIMMERMANN

Von unsichtbarer Schönheit und der Beschreibung des Unbeschreiblichen

in Konrads von Würzburg Partonopier und Meliur

FRANZISKA WENZEL

Hie ist der âventiure wurf gespilt. Anschauliches und uneigentliches Erzählen im Parzival Wolframs von Eschenbach

BEATRICE TRÎNCA

Spiegel der Transzendenz. Zum Speculum der Marguerite d'Oingt

FLORIAN KRAGL

Transfer ins Nichts. Eine poetologische Skizze zur Liebeslyrik

JAN MOHR

,Übertragung' zwischen Historizität und Heuristik.

Eine Zusammenfassung, mit Seitenblicken auf des Strickers Klugen Knecht

Verzeichnis der Autorinnen und Autoren

Tafeln 